\title{
Study on Damage Probability of High Voltage Electrical Equipment under Different Seismic Intensity
}

\author{
Rushan LIU \\ Institute of Engineering Mechanics, Key Laboratory for \\ Earthquake Engineering and Engineering Vibration, \\ China Earthquake Administration, Harbin, China \\ Email: liurushan@sina.com
}

\author{
Mingpan XIONG \\ Institute of Engineering Mechanics, Key Laboratory for \\ Earthquake Engineering and Engineering Vibration, \\ China Earthquake Administration, Harbin, China
}

\author{
Rongxing SHU \\ Institute of Engineering Mechanics \\ Key Laboratory for Earthquake Engineering and Engineering Vibration \\ China Earthquake Administration, Harbin, China
}

\begin{abstract}
Damages of transformer, potential transformer, current transformer, circuit breaker, disconnecting switch, arrester and other kinds of high voltage electrical equipments in substation under different seismic intensities have been summarized based on the damage data of electrical power system during Wenchuan earthquake. Damage probability density function curve and damage probability curve (vulnerability curve) of above high voltage electrical equipments have been established based on seismic intensity through normal distribution function and its accumulated function. Results show that transformer is the most vulnerable equipment which can be damaged in low seismic intensity, next to which are circuit breaker, arrester, PT, CT, disconnecting switch; the damage probability curves of PT, CT and disconnecting switch are very similar.
\end{abstract}

Keywords-seismic intensity; substation; high voltage electrical equipment; damage probability; vulnerability curve

\section{INTRODUCTION}

Power system is an important part of lifeline system and plays an important role in people's livelihood and national economy. Once it's damaged, it will cause great losses to the country and society. Substation is an important part of grid. High voltage electrical equipments such as transformer, circuit breaker, arrester, disconnecting switch, current transformer and potential transformer etc. are the most important part and the weak point of substations, which can be damaged easily during earthquakes. In previous earthquakes occurred at home and abroad, high voltage electrical equipments have all been damaged seriously, resulting in power failure in disaster areas and causing great difficulty in emergency rescue, people's livelihood and resettlement. Therefore, study on the vulnerability of high voltage electrical equipments not only provides a basis for the research of how to improve anti-seismic performance of electrical equipments, but also has important reference value for the rapid evaluation and emergency repair of electrical equipments after an earthquake.

Methods to research the anti-seismic performance and vulnerability of high voltage electrical equipments include theoretical analysis, simulation calculation, vibration table test and damage-based analysis etc. Since 1980s till now, many scholars at home and abroad have conducted a lot of researches on the anti-seismic performance of high voltage electrical equipments by adopting the first two methods [1]. Methods such as theoretical calculation, numerical simulation and vibration table test are more suitable for the analysis of earthquake response and the simulation of damage process and situation, and play a powerful role in the analysis and research of the anti-seismic performance and damage mechanism of equipments and the improvement of anti-seismic and vibration isolation technologies [2-4].

In the study, according to actual seismic data, based on samples of damaged high voltage electrical equipments, through statistical analysis, the damage probabilities of equipments under different seismic intensities are obtained, which have the most resemblance to actual earthquake damages. Not only can it provide the basis and reference for the anti-seismic performance of equipments, but also can often be used for analyzing damage risks of equipments under different earthquake intensities.

In 1980s, Pacific Earthquake Engineering Research Center (PEER) and Pacific Gas and Electric Company jointly established the anti-seismic performance database of substation equipments in California. The database records the damage data of electrical equipments in 60 substations of $230 \mathrm{kV}$ to $550 \mathrm{kV}$ during 12 earthquakes and presents the vulnerability curves of equipments based on the data, which have been widely used in the evaluation of power systems after disasters. Applied Technology Committee (ATC) presents the seismic vulnerability curves of all kinds of lifeline system equipments and facilities based on experts' experience[5] for Earthquake Emergency (FEM) Risk Analysis System of America (HAZAS) [6].

In recent years, Chinese scholars Meng Minjie and $\mathrm{Hu}$ Yujing et al. have studied on the vulnerability of oilimmersed high voltage transformers and electrical equipments connected to the bus bar [7, 8]; He Hailei et al. has presented the seismic vulnerability curves of transformers, bus bars and transmission towers [9]; Liu Zhenlin has presented the seismic vulnerability fitted curves 
of porcelain electrical equipments through Weibull distribution function[10]; Yang Changqing has been the first to present the space distribution of peak acceleration field (Wenchuan earthquake) through kriging interpolation method, to study on the relations between the damage probability of a type of equipments and the peak acceleration and the peak acceleration response spectrum and also analyze the failure mode under different peak acceleration values [11].

The above researches on the vulnerability of electrical equipments are all based on the research of vulnerability of the peak acceleration and peak acceleration response spectrum. However, although during the seismic damage prediction work carried out in large and medium-sized cities in China, the vulnerabilities of high voltage electrical equipments have been obtained, the results basically rely on experts' experience and theoretical prediction, which reduces the reliability of equipment vulnerability curves to some extent. In addition, American and Chinese electrical equipments are a little different and adopt different seismic intensity standards, so the results of research on the vulnerability of high voltage electrical equipments based on seismic intensities provided by Pacific Earthquake Engineering Research Center should not be applied to China directly.

In view of that, based on seismic damage data of 121 substations of $110 \mathrm{KV}$ and above in national grid distributed in the most seriously-damaged areas such as Mianyang, Deyang, Guangyuan and part of Chengdu during Wenchuan earthquake, the article has calculated the damage probability fitted curves of high voltage electrical equipments such as transformer, circuit breaker, potential transformer, current transformer, disconnecting switch and arrester through cumulative functions in normal probability density distribution.

\section{Statistical SAMPLES AND NUmber of Damaged SUBSTATIONS IN WENCHUAN EARTHQUAKE}

60 counties and cities were affected by Wenchuan earthquake and a total of 4,050,700 users suffered from the failure of power supply. The power grid of 10 counties including Pengzhou and Dujiangyan in Chengdu, Mianzhu, Shifang and Zhongiiang in Deyang, Beichuan, Jiangyou and Anxian in Mianyang, Qingchuan and Jiange in Guangyuan was seriously damaged. The direct economic loss of power facilities caused by the earthquake is about 7.1 billion Yuan, and the net loss of assets is about 5.64 billion Yuan, of which, Sichuan Electric Power Company suffered a loss of 5.43 billion Yuan [12].

According to the statistics of Sichuan Electric Power Test \& Research Institute [13], the overall situation of damaged substations is shown in tab. 1.
TABLE I. TABLE NUMBER OF DAMAGED SUBSTATIONS IN WENCHUAN EARTHQUAKE

\begin{tabular}{|c|c|c|c|}
\hline $\begin{array}{c}\text { Voltage } \\
\text { Grade/kV }\end{array}$ & $\begin{array}{c}\text { Number of } \\
\text { Original } \\
\text { Substations }\end{array}$ & $\begin{array}{c}\text { Number of } \\
\text { Damaged } \\
\text { Substations }\end{array}$ & $\begin{array}{c}\text { Number of } \\
\text { Reconstructed } \\
\text { Substations and } \\
\text { Substations to be } \\
\text { Reconstructed }\end{array}$ \\
\hline 500 & 18 & 1 & 1 \\
\hline 220 & 91 & 13 & 4 \\
\hline 110 & 400 & 66 & 5 \\
\hline 35 & 583 & 91 & 7 \\
\hline Total & 1092 & 171 & 17 \\
\hline
\end{tabular}

Power supply system in Sichuan Province mainly consists of the state grid assisted by power grid hosted by some local power supply companies. The seismogenic fault of Wenchuan earthquake lies on the edge of the basin, in the southeast direction of which is the plain area at the bottom of the basin. This area is densely populated with large demand for commercial power, therefore, power grid is distributed comprehensively and substations are mostly built at here. In this article, 121 substations distributed in most seriouslydamaged districts including state grid substations of $110 \mathrm{kV}$ and above in Deyang, Mianyang and Guangyuan districts, Dujiangyan, Pengzhou, Chongzhou, Wenjiang and Pixian districts in Chengdu, as well as substations hosted temporarily by state grid corporation in Aba district are selected as samples for the vulnerability study for high voltage electrical equipments. In Deyang district, there are one substation of $500 \mathrm{kV}$, six substations of $220 \mathrm{kV}$ and 35 substations of $110 \mathrm{kV}$; in Mianyang district, there are 7 substations of $220 \mathrm{kV}$ and 32 substations of $110 \mathrm{kV}$; in Guangyuan district, there are 4 substations of $220 \mathrm{kV}$ and 13 substations of $110 \mathrm{kV}$; in Dujiangyan, Pengzhou, Chongzhou, Wenjiang and Pixian districts (Chengdu), there are 2 substations of $500 \mathrm{kV}, 4$ substations of $220 \mathrm{kV}$ and 15 substations of $110 \mathrm{kV}$; in Aba district, there are one substation of $500 \mathrm{kV}$ and one substation of $220 \mathrm{kV}$ temporarily hosted by state grid. Most of the above substations are under 6-grade security, part of them are under 7-grade security.

The vulnerability of high voltage electrical equipments with different voltage grades varies. Especially, the specifications and manufacturing process of high voltage electrical equipments in $35 \mathrm{kV}$ substations and $110 \mathrm{kV} / 220 \mathrm{kV}$ substations are quite different, resulting in large difference in vulnerability. Therefore, only substations of $110 \mathrm{kV}$ and above are selected as samples in this article.

\section{Statistical Methods of Damage Probabilities FOR VARIOUS High Voltage Electrical EQUIPMENTS IN SUBSTATIONS}

Outdoor high voltage electrical equipments in substations such as circuit breaker, disconnecting switch, potential transformer, current transformer and arrester, except for transformer, are all structured with porcelain knobs, so during an earthquake, the most common damages are fracture or break of porcelain components. These porcelain knob components cannot be repaired but replaced once 
damaged. Therefore, the damage mode of these equipments is summarized as the " $0-1$ ", which means, there are only two types, the equipment is either damaged or not damaged, which are not necessary to be categorized into 5 damage grades as the building structure. In terms of transformers, during an earthquake, damages are mostly found on porcelain insulator, and damages on oil conservator, radiator and wheel fixing device can be found in high intensity earthquakes, even the turnover of transformer occasionally. However, the internal main structure of transformer cannot be damaged easily, there was no such case found in Wenchuan earthquake. No matter which form of damages are found on transformers, the loss ratios are all limited to a small range, which generally will not exceed $20 \%$ of the total cost. Therefore, just like other types of high voltage electrical equipments, the damages of transformers can also be categorized into two types without classification of damage grades.

Generally, one substation has one or more sets of working transformers and many sets of other types of high voltage electrical equipments. If the seismic intensity of a substation is $I$, then the damage probability of one type of high voltage electrical equipments in the substation is:

$$
R=n / N
$$

In (1), $R$ refers to the damage probability of one type of high voltage electrical equipments in the substation; $n$ is the number of damaged equipments in the substation; $N$ is the total number of this type of equipments in the substation.

By taking the damage probability of one type of equipments in each substation as a sample and adopting the substation samples, damage probability - seismic intensity fitted curves of each type of equipments (known as the vulnerability curves) can be calculated through a type of mathematical function.

There are various probability distribution functions, which can be adopted separately in terms of different distribution problems. Some scholars have studied the relation between the damage probability and the seismic peak value of transformers and bus bars, and presented fitted relation curves through logarithm normal distribution [9]. In addition, some scholars have studied the vulnerability of basic components of reinforced concrete and structures during earthquakes and found that it is appropriate to present the relation between their damages and earthquake peak acceleration (PGA) through algorithm normal distribution [14]' [15]. Therefore, it can be assumed that the PGA and vulnerability relation of all types of outdoor high voltage electrical equipments is in accordance with algorithm normal distribution. There is a certain linear relation between seismic intensities and the algorithms of PGA. In view of the relation between normal distribution and algorithm normal distribution, the relation between vulnerability of high voltage electrical equipments and seismic intensities can usually be fitted through normal distribution functions.

Normal distribution and algorithm normal distribution have the following relation: if $x$ is a random variable in normal distribution, then $\exp (x)$ is algorithm distribution; if $x$ is a random variable in algorithm normal distribution, then $\ln (x)$ is normal distribution.

If the random variable $x$ follows the normal probability distribution with the expected value of $\mu$ and the standard deviation of $\sigma$, then the probability density function and cumulative distribution function are:

$$
\begin{gathered}
f(x)=\frac{1}{\sigma \sqrt{2 \pi}} \exp \left[-\frac{(x-\mu)^{2}}{2 \sigma^{2}}\right] \\
F(x)=0.5+0.5 \operatorname{erf}\left(\frac{x-\mu}{\sigma \sqrt{2}}\right)
\end{gathered}
$$

In which, the function $\operatorname{erf}(x)$ is:

$$
\operatorname{erf}(x)=\frac{2}{\sqrt{\pi}} \int_{0}^{x} e^{-t^{2}} d t
$$

By adopting (3), damage probability curves of all kinds of high voltage electrical equipments under different seismic intensities can be obtained by fitting damage probabilities of equipments in each substation and the actual seismic intensity through the least square method.

\section{Results of Damage Probability Fitted CuRves of All Kinds of High Voltage EleCtrical EQUIPMENTS}

The probability and seismic intensity relation fitted curves of transformer, circuit breaker, disconnecting switch, current transformer, potential transformer and arrester are obtained based on substation samples. The fitted $\mu$ and $\sigma$ values of normal distribution cumulative functions of various electrical equipments are shown in tab. 2 .

TABLE II. TABLE NORMAL Distribution CURVE PARAMETER VALUES OF High Voltage Electrical EQuipment Damage Probability

\begin{tabular}{|c|c|c|}
\hline Equipment Type & Expected Value $\boldsymbol{\mu}$ & $\begin{array}{c}\text { Standard } \\
\text { Deviation } \boldsymbol{\sigma}\end{array}$ \\
\hline Transformer & 7.88 & 1.14 \\
\hline Circuit Breaker & 8.95 & 1.11 \\
\hline $\begin{array}{c}\text { Disconnecting } \\
\text { Switch }\end{array}$ & 9.60 & 1.36 \\
\hline Arrester & 9.21 & 1.28 \\
\hline $\begin{array}{c}\text { Current } \\
\text { Transformer }\end{array}$ & 9.50 & 1.48 \\
\hline $\begin{array}{c}\text { Potential } \\
\text { Transformer }\end{array}$ & 9.41 & 1.44 \\
\hline
\end{tabular}

Original sample data points and fitted damage probability distribution curves of various high voltage electrical equipments are shown in Fig. 1 ((a) to (f)). On Fig. 1, it is shown that, 1 . the damage probability of transformers under the seismic intensity of 7,8 or 9 is above $20 \%, 50 \%$ and $80 \%$ respectively, and under the seismic intensity of 10 , the 
damage probability of transformers is almost $100 \% ; 2$. As for other types of equipments, other than transformers, under the seismic intensity of 7 , there is the possibility for damage, but the damage probability is very small and mostly less than $4 \%$, and the damage probability of other types of equipments under the seismic intensity of 8,9 or 10 is less than $20 \%$, around $40 \%$ and over $60 \%$ respectively; 3 . Under different seismic intensities, the discreteness in damage probabilities of different types of high voltage electrical equipments is obvious. Take the substation as an example, in districts under low intensities such as 6 and 7, the damage probability of transformers in some substations can reach $100 \%$, while transformers in other substations are not damaged. In view of damage probability fitted curves, the damage probability of transformers is less than $30 \%$; 4 . In general, the number of transformers in a substation shall not be more than 3 , so under various seismic intensities, the values of sample damage probabilities are fixed and only 6 fixed values are obtained: $0.0,0.25,0.5,0.33$, and 0.66 and 1.0 , so there are many overlaps of sample points. Only few scattered sample points are shown on the figure. However, the numbers of other types of equipments in a substation are usually more, which can be reflected in more damage probability values on the figure.

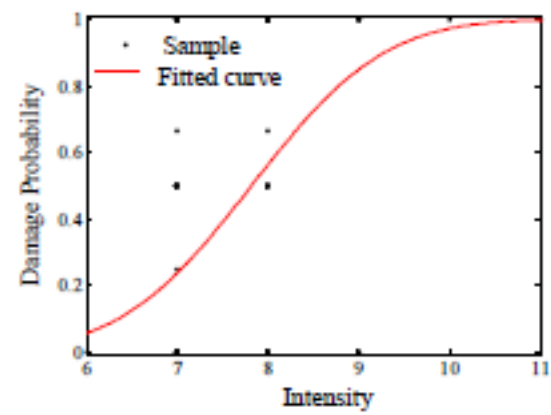

(a) Transformer

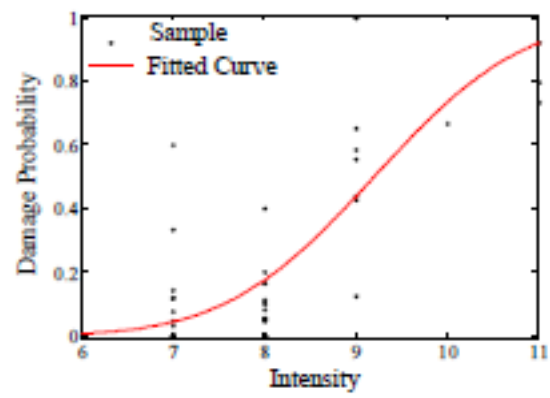

(d) Anester

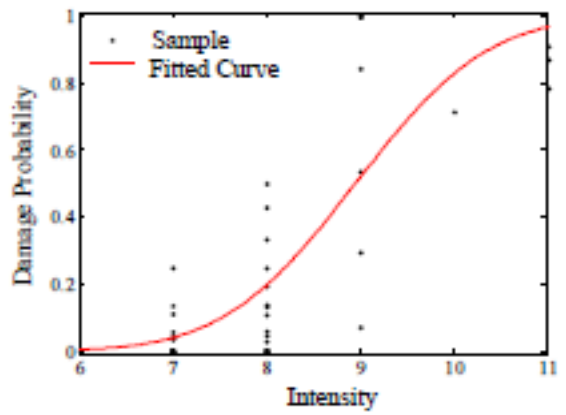

(b) Circuit breaker

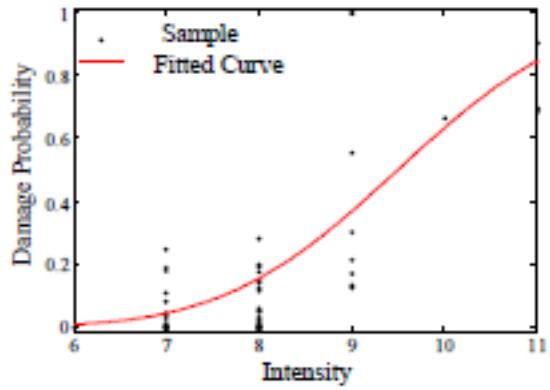

(e) Current transformer

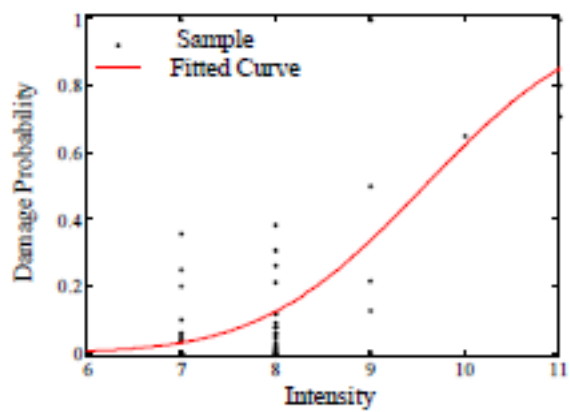

(c) Disconnecting switch

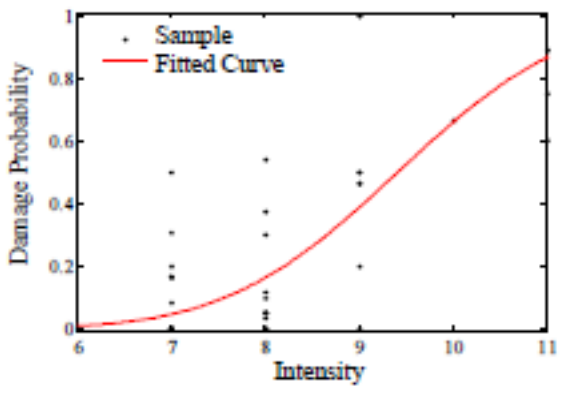

(f) Potential transformer

Figure 1. High voltage electrical equipment damage probability fitted curve and sample distribution.

Contrast of damage probability fitted curve and contrast of damage probability density curve of all kinds of high voltage electrical equipment are shown in Fig. 2 and Fig. 3.

It can be seen from Fig. 2 that transformers are easier to be damaged compared with other types of high voltage electrical equipments, its damage probability is obviously higher than other equipments; circuit breakers rank the second, followed by the arrester, PT, Ct and disconnecting switch, the damage probabilities of PT, CT and disconnecting switch are close.

It can be seen from Fig. 3 that under the seismic intensity of weak 8 , the damage probability density of transformers reaches the peak value, the number of damaged transformers will increase significantly; under the seismic intensity of weak 9, the damage probability density of circuit breakers reaches the peak value, the number of damaged circuit breakers will increase significantly; under the seismic intensity of strong 9, the damage probabilities of disconnecting switch, arrester, current transformer and potential transformer reach peak values, the number of damaged equipments will increase significantly.

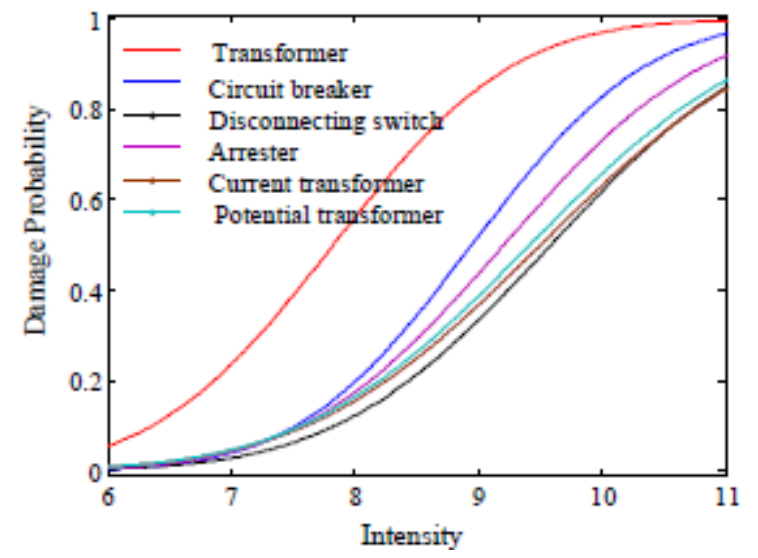

Figure 2. Damage probability curve contrast figure of all kinds of high voltage electrical equipment. 


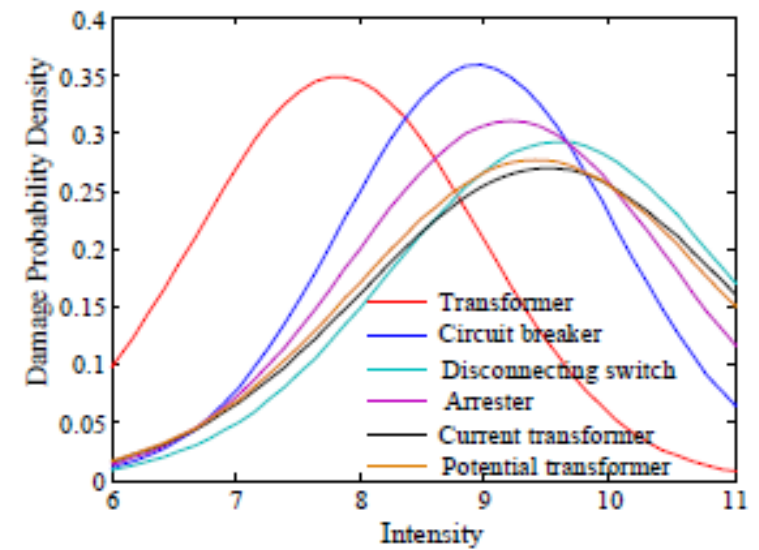

Figure 3. Damage probability density function curve contrast figure of all kinds of high voltage electrical equipment.

\section{CONCLUSION}

Based on the seismic damage data of 121 substations of $110 \mathrm{KV}$ and above distributed in the most seriously-damaged areas such as Mianyang, Deyang, Guangyuan and part of Chengdu during Wenchuan earthquake, the article has obtained the damage probability fitted curves of high voltage electrical equipments such as transformer, circuit breaker, potential transformer, current transformer, disconnecting switch and arrester etc. through cumulative functions in normal probability density distribution, also known as the "vulnerability curve". Fitting results show that during earthquakes, transformers are the easiest to be damaged, its damage probabilities are high even under low seismic intensities, circuit breakers and arresters are the second easiest to be damaged; the PT, CT and disconnecting switch have relatively better anti-seismic performance and their damage probability curves are very similar, which can be considered as the same type of damage probability curve. Transformers are the weak part of substations and also the main factor for causing substation failure during earthquakes. Researches on methods to improve the anti-seismic, vibration-absorbing and isolation performances of transformers must be carried out urgently. High voltage electrical equipment damage probability curves can be used for rapid assessment of earthquake damage and economic loss of power equipments and provide an important reference for the power department during emergency rescue and function recovery after earthquakes.

The magnitude of Wenchuan earthquake is high. The earthquake has affected many areas and caused serious damages. Damage samples are collected from areas under low, medium and high seismic intensities, which provides basic materials for the vulnerability research of high voltage electrical equipments. However, vulnerability curves require more damage data and need to be improved by accumulating more samples, especially samples from areas under the seismic intensity of 10 or 11 . Only in this way, the vulnerability curves of high voltage electrical equipments can be more reliable.

\section{ACKNOWLEDGMENT}

This work was supported by Foundation for National Science and Technology Supporting Program of China (2015BAK17B05-4), Special Fund for Earthquake Industry (201508023), Program for Innovative Research Team in China Earthquake Administration.

State Grid Sichuan Electric Power Company and power supply companies in various areas have also supported the research strongly and provided a lot of precious substation damage materials. We are here to express our deepest gratitude to them.

\section{REFERENCES}

[1] WEN Bo, NIU Ditao, ZHAO Peng. An overview on aseismic reliability research in electric power system[J].Journal of Catastrophology,2007, 22(4):86-90. (in Chinese)

[2] Bellorini S, Salvetti M, Bettinali F, et al. Seismic qualification of transformer high voltage bushings[J]. Power Delivery, IEEE Transactionson, 1998, 13(4): 1208-1213.

[3] Saadeghvaziri M A, Ashrafi A, Allaverdi N H, et al. Seismic Response and Rehabilitation of Critical Substation Equipment[C]. Proceedings of 13th World Conference on Earthquake Engineering, IAEE, August 1-6, Vancouver, B. C., Canada. 2004.

[4] XIE Qiang, ZHU Rui-yuan. Research state and development of seismic performance of large transformer[J]. Transformer, 2011, 48(01):25-31.(in Chinese)

[5] ATC. ATC 13 Earthquake Damage Evaluation Data for California[R]. Advanced Technology Council, 1985.

[6] FEMA\&NIBS. Earthquake loss estimation methodology-HAZUS 1999 [R]. Washington, DC: Federal Emergency Management Agency and National Institute of Building Science, 1999.

[7] MEMG Minjie, CHEN Ling-li, YE Zhiming. Modeling and seismic fragility analysis of transformers $[\mathrm{J}]$. World Earthquake Engineering, 2007,23(3):163-167.(in Chinese)

[8] HU Yujing, XIE Qiang. Seismic Vulnerability of substation equipment interconnected by rigid bus[J]. Electric Power Construction, 2010, 31(7):22-28. (in Chinese)

[9] HE Hailei,GUOJianbo,XIEQiang. Vulnerability analysis of power equipment caused by earthquake disaster[J].Power System Technology,2011,35(4): 25-28. (in Chinese)

[10] LIU Zhenlin, DAI Zebing, LU Zhicheng. Weibull distribution based seismic vulnerability analysis of porcelain equipment[J].Power System Technology,2014,38(4):1076-1081. (in Chinese)

[11] YANG Changqing. Vulnerability analysis of high voltage electrical equipment based on ground motion parameters [D]. Harbin: Institute of Engineering Mechanics, CEA, 2011. (in Chinese)

[12] China Earthquake Administration Wenchuan Earthquake Emergency Headquarters. Wenchuan earthquake disaster assessment report[R]. Beijing: China Earthquake Administration ,2008. (in Chinese)

[13] Sichuan Electric Power Experiment Research Institute. Wenchuan earthquake sichuanpower grid electrical equipment damage report[R],2008. (in Chinese)

[14] H. Hwang, LIU Jingbo. Seismic fragility analysis of reinforced concrete bridges[J]. China Civil Engineering Journal,2004, 37(6):4751. (in Chinese)

[15] LIU Yangbing. Research on seismic performance and fragility for steel-concrete composite structural systems[D]. Beijing: Tsinghua University,2009.(in Chinese) 